Forum: Viewpoint

\title{
Successful Adaptive Management-The Integration of Research and Management
}

\author{
Kimberly J. Reever Morghan, ${ }^{1}$ Roger L. Sheley, ${ }^{2}$ and Tony J. Svejcar ${ }^{3}$ \\ Authors are ${ }^{1}$ Ecologist, ${ }^{2}$ Weed Scientist, and ${ }^{3}$ Research Leader, Eastern Oregon Agricultural Research Center, \\ USDA-ARS, 67826-A Highway 205, Burns, OR 97720.
}

\begin{abstract}
Adaptive management is a way for managers to do their jobs in the face of uncertainty and learn by doing. Managers gain greater knowledge of their systems by testing different strategies during the management process. The term "adaptive management" is used often, but there is confusion about exactly what adaptive management is, and managers are hard-pressed to find any clear guidelines for implementing it. As a result, they can find the process of moving from the concept of adaptive management to the actual practice intimidating; they need a clear understanding of adaptive management before they can begin to use it. Luckily, adaptive management is not as complicated as the literature sometimes makes it appear. The process of adaptive management involves formulating questions, selecting alternative techniques to test these questions, and testing these techniques on the landscape. Care is taken to measure those system responses that best tell whether the system is moving toward site objectives, and results are fed back into the decision process. We argue that there are 2 strategies that can be used to improve the success of adaptive management. The first is to start with a simple adaptive management plan and then add complexity over time. The second is to include researchers in all stages of the process to benefit from their expertise in ecology, experimental design, and data analysis. Although adaptive management takes time, rewards include increased understanding of the system, a management program that is scientifically valid, and a management strategy tailored to a particular site. In this paper we briefly explain adaptive management and then offer a stepby-step process for developing and implementing adaptive management in small reserves or on private lands. We believe increased understanding of adaptive management will lead to its widespread use and will ensure that more people benefit from its strengths.
\end{abstract}

Key Words: decision-making, land management, public input

\section{INTRODUCTION}

Lately we have been hearing quite a bit of enthusiastic talk about adaptive management at seminars, workshops, and conferences. This is a management strategy that allows managers to conduct actual land management while simultaneously evaluating different management techniques to see which are the most effective. In contrast to traditional management, which typically applies one management technique to an entire site, adaptive management allows testing of multiple different management strategies and comparison between them. However, despite all the talk about adaptive management, there is still confusion about exactly what adaptive management really is (Stankey 2003; Stankey et al. 2003; Schreiber et al. 2004), and much of what is currently called "adaptive" is not really designed to take full advantage of the strengths of this technique (Walters 1997). One great shortcoming in the literature is the lack of clear, explicit guidelines on how a manager can develop and implement adaptive management; the few papers that address the underlying process usually limit themselves to a general diagram of the steps (e.g., Borman et al. 1994; Bearlin et al. 2002). As a result, it can be daunting for managers to make the jump from adaptive management as an idea to adaptive management as a practice. A reading of the classics of adaptive management (e.g., Holling 1978; Walters 1986) offers

Correspondence: Kimberly J. Reever Morghan, Eastern Oregon Agricultural Research Center, USDA-ARS, 67826-A Highway 205, Burns, OR 97720. Email: Kimberly.Morghan@ oregonstate.edu

Manuscript received 14 April 2005; manuscript accepted 19 September 2005. some good information, but it also leaves managers feeling that they must have training in modeling and must hold large workshops and modeling sessions before they can even figure out their management questions. Most managers, however, are well aware of their main management problems and can easily explain their key management objectives. In this paper we offer managers both a better understanding of adaptive management and some clear steps to follow for developing and implementing adaptive management in the context of their own management challenges. These steps are relevant to developing an adaptive approach to management for managers working at the scale of refuges, reserves, and private lands.

\section{DEFINING “ADAPTIVE MANAGEMENT”}

A survey of the literature will unearth a few examples of true adaptive management, but more commonly one will find the "adaptive management" label placed on papers that describe traditional management with some rudimentary monitoring added on. For example, Stankey (2003) surveyed adaptive management areas in the Pacific Northwest and concluded that "adaptive management has been largely confined to rhetorical language and cosmetic attention" (p. 173). The simplest definition of adaptive management is "learning by doing." However, it is difficult to find information on how to design management for learning or even what learning is in the context of adaptive management (Stankey et al. 2003). In adaptive management, learning involves using actual management to test different management alternatives and gain knowledge about a system. 
The result is a dynamic management strategy based on the knowledge of which techniques worked and which did not.

The 2 distinguishing characteristics of adaptive management are that, first, management is planned and conducted as an experiment, and second, there is a direct feedback loop between researchers and managers, so management decisions can be improved as research provides information about the system (Halbert 1993). What makes adaptive management so powerful is that management can proceed despite uncertainty about the outcomes. Adaptive management does not need to wait until managers have exhaustively researched all management alternatives, but instead is developed using the best information available. As management proceeds, techniques that do not work are weeded out and replaced by others. Thus, management is based on experimental comparison between alternative management strategies and increases the understanding of the system. As additional management strategies are tested, the resulting management plans are refined. As time passes, understanding of the system increases, which results in a better ability to adjust and modify management to account for such things as yearly climate variations, new management objectives, or other challenges unforeseen at the beginning of the process. The information provided by the process is tailored to the site, which is a vast improvement over management based on generalizations from the literature based on the effectiveness of management techniques at distant locations.

\section{CREATING SUCCESSFUL ADAPTIVE MANAGEMENT PROJECTS}

There have been few examples of successful adaptive management projects, so we have not yet proved that adaptive management works (Lee 1999). Indeed, part of the lack of successful adaptive management is that few managers develop adaptive management plans and even fewer of these plans are used to guide actual management (Taylor et al. 1997; Walters 1997). Managers are often told to use adaptive management, but are given little training or support (e.g., Stankey et al. 2003). In addition, adaptive management plans may run the risk of trying to do too much at the onset; this includes designs that attempt to answer too many questions, test too many treatments, or incorporate too complex a monitoring design. Managers who are not trained in adaptive management may look at these complicated plans and see them as a large amount of extra work with no readily apparent benefit. In this situation, it may be difficult for a manager to feel enthusiastic about implementing adaptive management. We suggest 2 strategies be used to increase the success of moving from adaptive management as an idea to adaptive management as a process; these 2 strategies are, first, to start simple and, second, to harness the skills of trained researchers.

Starting simple means that the first foray managers make into adaptive management should be based on simple management plans. These plans should target a small area, ask a few basic questions, and act as a pilot study for adaptive management (Taylor et al. 1997). Simple adaptive management plans make the process and its benefits more apparent and help generate enthusiasm for the practice. These simple adaptive management plans may also provide quicker successes, which can help the plan gain wider support (Taylor et al. 1997). More complexity can be included after the management team has become comfortable with this basic approach (Smith et al. 1999). After concerned parties see the value of the simple plan and develop support for it, increasing complexity can be added as the manager identifies new critical research questions.

The inclusion of researchers with some understanding of adaptive management into management teams can also improve adaptive management successes. According to Taylor et al. (1997), adaptive management plans should be designed with the input of both managers and researchers. Researchers can provide expertise in experimental design and statistics, whereas managers offer a great understanding of their systems, their stakeholder concerns, and their management capabilities and limitations. Through discussion and compromise, researchers and managers can find a balance between the researchers' desire for a solid experimental design and statistical rigor and the managers' knowledge about the limitations that the site and available resources place on the experimental design as well as their need for management relevance. When managers and researchers work together, the resulting adaptive management plan will be both relevant to a given site's important management questions and practical. Researchers can suggest management alternatives from the literature, and managers can determine which of those alternatives are feasible. Collaboration between researcher and manager ensures that management resources are used wisely and the efforts of adaptive management are best aimed at the needs of the site.

\section{THE STEPS OF ADAPTIVE MANAGEMENT}

In this section we offer managers a step-by-step plan for developing and implementing an adaptive management program. Although the final adaptive management design varies with the needs of a particular site, all adaptive management plans go through a similar series of development and implementation steps.

Step 1. The first and most critical step of adaptive management is the development of the management questions. Through discussion of the site and its management concerns, the management team ensures that the adaptive management plan addresses key questions of management significance (Lee 1993). Collaboration between researcher and manager ensures that the adaptive management plan is relevant to the needs of management.

Step 2. In the second step, the management team synthesizes information about previous management successes and failures at the site as well as scientific literature and reports on management successes and failures at similar sites elsewhere. This synthesis of information is then used to generate a series of alternative management hypotheses for the site.

Step 3. The third step is the development of the initial adaptive management plan. The researcher and manager choose which of the alternative management hypotheses generated in step 2 are feasible. They discuss the extent of the adaptive management plan, the number of replications and plot sizes, and incorporate any limitations that the site or management resources place on the design. The researcher develops a design using the best experimental design possible, keeping in 
mind that the constraints of the site may require dealing with more confounding factors and accepting less statistical certainty than in a formal experiment (Taylor et al. 1997).

Step 4. In the fourth step, the management team ensures that stakeholders are informed of the plan and that stakeholder concerns are incorporated. The team meets with all stakeholder groups, such as site users, public interest groups, and environmental groups to encourage feedback and address concerns about the project. This is a great opportunity to present the adaptive management plan to the public, develop positive support for the project, and prevent problems caused when groups feel they have been kept out of the management process. Early input from the public ensures that the team can do the best science (Graham and Kruger 2002). If stakeholders feel that the adaptive management plan goes against their interests, then they can put great pressure on managers to stop a management plan or may even sabotage it (Lee 1999). Thus, public involvement in the project is highly important.

Step 5. In the fifth step, the concerns of stakeholders are incorporated into the adaptive management plan. In this step, experimental designs may be changed and treatments may be modified, moved, or replaced. Some major compromises might be needed, and it may not be possible to test some of the areas of greatest uncertainty. Controversial treatments may need to be reassigned to less politically sensitive areas of the site (Bormann et al. 1994). Strong political pressure can stop an experiment when there is fear of a negative response to management (Volkman and McConnaha 1993). In addition, compromise treatments run the risk of being too weak to create the desired management effect (Walters 1997). However, incorporating as many stakeholder concerns as possible is vital to public support of the project.

Step 6. In the sixth step, the management team implements the adaptive management plan. The modified design from step 5 is applied to the site, and these treatments are continued until measurable changes occur in the system. The amount of time this step takes is determined by the ecology of the site and the strength of the management treatments.

Step 7. The seventh step is the collection and analysis of the response data. Monitoring data are collected from each treatment, and the analysis compares the responses between treatments and against any controls. Adaptive management experiments are implemented at the scale of management, which means they typically cover larger areas than those used for traditional scientific experiments. Managers often work in sites made up of a series of heterogeneous units with varied management histories, making it difficult to partition sites into a large number of similar experimental units and reducing the number of possible replicates (Walters 1986). Limitations in resources, time constraints, and costs may also make it impractical to replicate treatments more than a handful of times (Linnell Nemec 1998). Because of the large scale and low number of replications, treatment response differences may not be significant at the $P<0.05$ threshold that many studies use. Instead, differences should be compared using criteria based on "management significance"-did one treatment bring the system much closer to management objectives than the others? Depending on the system, detecting change may require monitoring for significant periods of time; however, acquiring these data is critical to the success of the adaptive management plan.

Step 8. In the eighth step, the conclusions generated by the data analysis are used to update the understanding of the site and are incorporated back into the management plan. Treatments should be continued over time to gain better understanding about how yearly and decadal climatic variation affects the treatment response. Treatments that shift the system away from the desired objective may be modified or replaced with other treatments, but caution must be taken to not stop a treatment before its full effect is understood. When left to continue over longer time scales, treatments that appeared to have no effect or even a negative effect in the short term may eventually drive the system in the desired direction, while initially positive responses to other treatments may prove to be short-lived. Steps 6 through 8 can be continued indefinitely, evaluating additional treatments and generating a greater and greater understanding of the system and the best management practices.

\section{WHAT DOES ADAPTIVE MANAGEMENT OFFER?}

The main strength of adaptive management is the fact that managers are able to manage in the face of uncertainty and "learn by doing." As adaptive management progresses, managers develop a greater understanding of their system and which management techniques work best under a variety of conditions. We believe that, for managers, using the strategy of starting with simple adaptive management plans and harnessing the skills of researchers in the management process will greatly improve the effectiveness and success of adaptive management. By following the general guidelines presented in this paper, more managers can move from traditional to adaptive management strategies and can benefit from this powerful technique.

\section{ACKNOWLEDGMENTS}

We thank Matt Rinella and Jane Mangold for their helpful editorial suggestions.

\section{LITERATURE CITED}

Bearlin, A. R., E. S. G. Schreiber, S. J. Nicol, A. M. Starfield, and C. R. Todd. 2002. Identifying the weakest link: simulating adaptive management of the reintroduction of a threatened fish. Canadian Journal of Fisheries and Aquatic Sciences 59:1709-1716.

Bormann, B. T., P. G. Cunningham, M. H. Brookes, V. W. Manning, and M. W. Collopy. 1994. Adaptive ecosystem management in the Pacific Northwest. Portland, OR: US Department of Agriculture, Forest Service, Pacific Northwest Research Station. General Technical Report PNW-GTR-341. $22 \mathrm{p}$.

Graham, A. C., and L. E. Kruger. 2002. Research in adaptive management: working relations and the research process. Portland, OR: US Department of Agriculture, Forest Service, Pacific Northwest Research Station. Research Paper PNW-RP-538. $55 \mathrm{p}$.

HALBERT, C. L. 1993. How adaptive is adaptive management? Implementing adaptive management in Washington state and British Columbia. Reviews in Fisheries Science 1:261-283.

HoluING, C. S. 1978. Adaptive environmental assessment and management. London: John Wiley and Sons. $398 \mathrm{p}$. 
LeE, K. N. 1993. Compass and gyroscope: Integrating science and politics for the environment. Washington, DC: Island Press. 243 p.

LEE, K. N. 1999. Appraising adaptive management. Conservation Ecology 3(2):3. Available at: http://www.consecol.org/vol3/iss2/art3. Accessed 31 March 2004.

Linnell Nemec, A. F. 1998. Design of experiments. In: V. Sit and B. Taylor [eds.]. Statistical methods for adaptive management studies. Victoria, BC, Canada: British Columbia Ministry of Forests, Research Branch. Land Management Handbook No. 42. p 9-18.

Schreiber, E. S. G., A. R. Bearlin, S. J. Nicol, and C. R. Todd. 2004. Adaptive management: a synthesis of current understanding and effective application. Ecological Management \& Restoration 5:177-182.

Simith, A. D. M., K. J. Sainsbury, and R. A. Stevens. 1999. Implementing effective fisheries-management systems-management strategy evaluation and the Australian partnership approach. ICES Journal of Marine Science 56:967-979.

StAnKEY, G. H. 2003. Adaptive management at the regional scale: breakthrough innovation or mission impossible? A report on an American experience. In: B. P. Wilson and A. Curtis [EDS.]. Proceedings of the 2002 Fenner Conference on the Environment: Agriculture for the Australian Environment; 24-25 July 2002; Canberra, Australia. Alsbury, Australia: Johnstone Center, Charles Stuart University. p 159-177.

Stankey, G. H., B. T. Bormann, C. Ryan, B. Shindler, V. Sturtevant, R. N. Clark, and C. Pнilpot. 2003. Adaptive management and the Northwest Forest Plan: rhetoric and reality. Journal of Forestry 101:40-46.

Taylor, B., L. Kremsater, and R. Ellis. 1997. Adaptive management of forests in British Columbia. Victoria, BC, Canada: British Columbia Ministry of Forests, Forest Practices Branch. $93 \mathrm{p}$.

Volkman, J. M., and W. E. McConnaha. 1993. Through a glass, darkly: Columbia River salmon, the Endangered Species Act, and adaptive management. Environmental Law 23:1249-1272.

Walters, C. 1986. Adaptive management of renewable resources. New York, NY: Macmillan Publishing Company. $374 \mathrm{p}$.

WALTERS, C. 1997. Challenges in adaptive management of riparian and coastal ecosystems. Conservation Ecology 1(2):1. Available at: http://www.consecol.org/ vol1/iss2/art1. Accessed 24 June 2004. 